\title{
Same-sex Sexuality and Childhood Gender Non-conformity: a spurious connection
}

\author{
LORENE GOTTSCHALK
}

\begin{abstract}
Biological and hormonal theories of same-sex sexuality are usually based upon an assumption of congenital gender inversion, that is, that a lesbian is in some way masculinised and a gay man in some way feminised. Commonly, and also because of the assumption of biology, such evidence of gender inversion is sought in childhood. In this paper I present a challenge to the theory that childhood gender non-conformity is associated with homosexuality, noting in particular that discussions of gender non-conformity and 'homosexuality' do not attempt to explain the experiences of heterosexual women. By demonstrating that childhood gender non-conformity has been wrongly associated with same-sex sexuality and posing an alternative explanation for childhood gender non-conformity, it is my intention to present a challenge to the theory that same-sex sexuality is related to congenital gender inversion.
\end{abstract}

\section{Introduction}

For many, homosexuality (or same-sex sexuality) seems to be inextricably linked with gender. Dominant ways of thinking about same-sex sexuality, that is, that congenital, but inverted gender differences underpin the essence of the 'homosexual' person, have evolved from the work of the late nineteenth, and early twentieth, century sexologists (Ellis \& Symonds, 1897; von Krafft-Ebing, 1906; Bloch, 1908). Ellis and Symonds (1897, p. 87) used the term congenital gender invert and inversion to define a 'homosexual' as a person who possesses characteristics of the opposite sex. Public opinion was influenced by the work of the sexologists and also provided the basis for later empirical research. For example the idea of gender inversion is evident in early (e.g., Kallman, 1951) and more recent biological theories of 'homosexuality' (e.g., Bailey \& Pillard, 1991; and LeVay, 1993, 1996). Most of their theories too, are predicated on the belief that there are essential gender differences, which have in some way become inverted. Such gender inversion is believed to be evidenced by gender non-conforming characteristics and behaviour in childhood. Gender non-conformity is believed by many researchers and theorists of same-sex sexuality to be the behavioural expression of congenital gender inversion. Hence from such a perspective, a 'homosexual', that is, a gender invert, will behave in gender non-conforming ways from early childhood. Childhood gender 
non-conformity inevitably includes stereotypical activities such as avoidance of rough and tumble play for boys and engaging in same for girls, commonly known as tomboy and sissy behaviour (see Phillips \& Over, 1995; Bem, 1996; Haldeman, 2000; also discussed in Rottnek, 1999)

The concept of congenital gender inversion in same-sex sexuality therefore seems to be based on the assumption that there is a correct or essential way to be female or male. Theories of the aetiology of same-sex sexuality then, seem to be based on a combination of widely accepted, though unproven, assumptions. These are, an assumption of the biological nature of a same-sex sexual orientation, the assumption of an essential or biological nature of gender, the assumption of a relationship between gender and same-sex sexual orientation, and a belief in the essential or biological nature of that relationship.

Feminist theorists (see for example Kitzinger, 1987; Jeffreys, 1996), oppose any suggestion of essential gender differences and would argue that such a concept is necessary for the maintenance of rigid gender categories that underpin compulsory heterosexuality and male dominance. Feminist approaches reject the idea that same-sex sexuality is about gender inversion. A radical feminist perspective of sexuality is based upon social constructionism (Jackson, 1978, 1996; McKinnon, 1989; Jeffreys, 1997). This perspective recognises that the sexual self is moulded by social forces and conscious will rather than by any element of biology. This means that all human beings are born with the potential to be sexual, rather than with a particular sexual orientation, and that the direction of sexual preference, or sexual orientation, is socially determined, and influenced by the values and social arrangements of the dominant culture.

This feminist perspective of sexual orientation was explored in my research. This research included an examination, over three historical periods, of the influence on women becoming lesbians, of society's belief systems about same-sex sexuality on their experiences and their interpretations of events, at the time they formed a lesbian identity. By belief systems I refer to the dominant values, attitudes and beliefs, held by the majority of people within a culture. Specifically my objectives in this study were:

(a) to establish the relationship between society's dominant beliefs systems about samesex sexuality, and (i) women's perceptions and understanding about how they became lesbians, (ii) women's experience of forming a lesbian identity, and (iii) their lesbian lifestyle choices;

(b) to explore whether understanding of feminist challenges to essentialist constructions of gender, and sexuality empowered women to reject heterosexual relationships and enter lesbian relationships.

For this research I chose a feminist methodology. My objective in choosing a feminist methodology was to redress the imbalance of androcentric research about same-sex sexuality. I wished to demonstrate that knowledge of gender categorisation is critical to gaining a complete understanding of both lesbianism and male same-sex sexuality. Finally and most importantly I wished to demonstrate that women's experiences cannot be subsumed under the male generic. For this project I sought to tell women's stories from the understanding and perspective of the women involved. I therefore adopted the recommendation of Toby Jayaratne (1983) by using a multi-method approach for this study and combining qualitative and quantitative data collection methods.

This research was conducted using a combination of questionnaires and interviews. The questionnaire was used as an exploratory tool to determine the aspects of society's dominant belief systems about homosexuality, such as contact with medical professionals, 
images portrayed in the popular media, and other factors that influenced women's perceptions and understanding about their lesbianism. From the questionnaire responses I identified themes and highlighted those areas to be explored in the interviews. The interviews were used to clarify, validate and extend the information in the questionnaires. Fifty-six women were interviewed.

The interview used open-ended questioning plus story-telling technique. I used the story-telling method because I wanted to give the women the opportunity to tell their stories without being directed by me. I interjected only for clarification and more detail on a point they had made. In particular, points of clarification and more information were sought on comments made by respondents about: (a) feelings of difference; (b) crushes on teachers, women or other girls; (c) gender non-conformity, especially in childhood; and (d) the influence of feminism.

For my respondents, interpretation of issues of gender and gender inversion differed according to the ideologies to which they were exposed at the time they became lesbians. For example, the emphasis and meaning women gave to their feelings of 'being different' to other people, and childhood gender non-conformity differed significantly as the dominant ideology about sexuality changed.

The idea that childhood gender non-conformity is an indication of adult same sex sexuality is examined and challenged in this paper. To do this I have drawn on the stories told by the women who participated in my study, about their experience of childhood gender non-conformity and the meaning they gave to such experiences.

\section{Ghildhood gender non-conformity}

Theories connecting gender and same-sex sexuality rely to a great extent on the idea of childhood gender non-conformity. The 'evidence' spoken of in support of biological theories for same-sex sexuality usually include the recollection by adult 'homosexuals' of gender dysphoria and gender non-conformity in childhood (see, for example, Troiden, 1979, 1989; Coleman, 1982; Bem, 1996; Rottnek, 1999). The biological causes for gender inversion are believed to be caused by conditions such as hormonal imbalances, that is, an overdose or under-dose of male hormones (discussed in Byne \& Parsons, 1993), and/or feminised or masculinised brains (LeVay, 1993). Given such assumptions the 'homosexual' male is clearly seen to be feminised and the lesbian is seen to be masculinised. Such ideas of congenital gender inversion have become a constant part of the dominant ideology about sexuality and have been reinforced by the inclusion in the American Diagnostic Statistical Manual of Mental Disorders (DSM) of the category Gender Identity Disorder (GID) (discussed in Rottnek, 1999; see also Meyenburg, 1999; Haldeman, 2000).

Gender Identity Disorder pathologises gender non-conforming behaviour in children. By doing so, the idea of gender difference is essentialised. According to the DSM-IV children with GID have a 'marked preoccupation with traditionally feminine (masculine) activities' (see Minter, 1999, p. 10) including cross-dressing and avoidance of 'rough and tumble play' for boys and engaging in 'rough and tumble play' for girls. The gendered behaviours described in the DSM are stereotypes rejected even by early feminists such as Oakley (1972) as having any essential basis, but which persist not only in the popular media but also in sectors of the scientific and medical professions, especially in discussions of GID. That such so-called gender deviant, or gender non-conforming, activities described above are considered to be 'abnormal' activities for healthy children begs the 
question of what is normal, who decides what is normal and the reasons for their decision. These questions will be revisited later in this paper.

On the surface, it looked as though the removal from the DSM-II in 1973 of 'homosexuality', and the inclusion in the DSM-III in 1980 of GID, served to separate the connection of gender and sexuality. In reality, however, the move not only reinforced ideas of essential or biological gender differences separating women and men, but it also indirectly reintroduced the connection of gender and sexuality. For example some theorists and members of the medical profession view GID as a pre-homosexual condition, believing that if GID in childhood is treated promptly a later homosexual condition may be prevented (Minter, 1999, p. 12). Mass (1990) suggests that through the inclusion of GID, American Psychiatry had subtly reintroduced homosexuality as a mental illness. Burke (1996) too suggests that the inclusion of GID in the DSM was a deliberate ploy by those who objected to the removal of homosexuality as a mental illness in 1973. Indeed, according to Haldeman (2000) the GID literature often discusses GID and sexual orientation as though they are interconnected. Whilst there are those who disagree that same-sex sexuality may be prevented, their belief in an essential or biological 'homosexuality' is revealed. For example, it is of interest to note the comment about the research of Green in both 1985 and 1987 (cited in Minter, 1999) who evidently found that for children treated for GID there was 'no impact (on adult sexual orientation) most of the children grow up to be lesbian, gay or bisexual' (Minter, 1999, pp. 12-13). This comment reveals a belief that the underlying natural sexuality of such children is 'homosexual', that their sexual orientation is immutable and that their 'GID' was a manifestation of their true sexuality. Such views are still held. Pleak (1999, p. 43) points out that parents who bring their 'gender atypical' children to a therapist, do so because of a concern that their child is pre-homosexual and in the hope that treatment will prevent adult homosexuality. Whilst Haldeman (2000) is against treatment of children for GID to prevent adult homosexuality, his reasons are a belief in the immutability of sexual orientation.

Enthusiasm for the treatment of GID varies. Psychiatrist Richard Pleak (1999, p. 35) points out that it is only those who are 'very extensively cross gendered who would generally be diagnosed as having GID.' Haldeman (2000) however believes that a child could be diagnosed with GID on the basis of engaging in stereotypical gender non-conforming play. Corbett $(1998,1999)$ furthermore, sees the labelling of gender non-conforming behaviour as pathological to be due to a reluctance by mental health professionals to recognise the reality of gender variances. Views about GID such as Corbett's are underpinned by arguments made in existential psychotherapy. DuPlock, for example points out that in traditional abnormal psychology deviation from what is considered 'normal' is pathologised and thus seen to require treatment. In reflections of aversion therapy historically practised on gay men he maintained, 'The search for normality then, and the wish to move transgressors towards it, appears increasingly pointless and, at worst, enormously destructive' (DuPlock, 1997, p. 2). The DSM, he contends, though intended to be scientific tends to focus on the individual's ability to adapt to the 'normal'. While acknowledging the existence of emotional problems that may require some therapy he notes that the meaning given by professionals to those problems is neither fixed nor immutable, but rather it is socially constructed (DuPlock, 1997, p. 2).

In this paper I present evidence that the connection between gender non-conformity and adult sexuality too is socially constructed. To present a challenge to the theory that childhood gender non-conformity is associated with same-sex sexuality, I firstly challenge 
notions of gender dysphoria and secondly point out that discussions of gender non-conformity and same-sex sexuality do not attempt to explain the experiences of heterosexual women in particular. By posing an alternative explanation for childhood gender non-conformity and demonstrating that many women perceive their lesbianism to be a choice, I also present a strong challenge to theories of a biological basis for same-sex sexuality.

In order to demonstrate these points it is necessary to briefly examine research into 'homosexuality' and 'homosexual' identity formation that discusses childhood gender non-conformity. I then demonstrate how many gay men and lesbians, including lesbians in my study, draw on those dominant ideologies to give meaning to their experiences and how those meanings change as the dominant ideology changes. I then point out the androcentricism and gender bias inherent in these theories which has allowed the experiences of heterosexual women to be made invisible. I do this through a critical examination of the theories of psychologists Gabriel Phillips and Ray Over (1995) who examined the recalled childhood experiences of a group of lesbians and heterosexual women in Australia and Daryl Bem's (1996) theory of the 'exotic becomes erotic'. I conclude this paper with a radical feminist interpretation of childhood gender non-conformity and draw also on my own research to support radical feminist theories.

\section{Research into childhood gender non-conformity}

Childhood gender non-conformity was often spoken of in early models of homosexual identity formation (Dank, 1971; Plummer, 1975; Troiden, 1979, 1989; Green, 1980, cited in Minton \& McDonald, 1984; Bell, Weinberg \& Hammersmith, 1981; Plummer, 1981; Coleman, 1982; Money \& Ehrhardt, cited in Coleman, 1982; Minton and McDonald, 1984). In models of homosexual identity formation, this is the stage that is usually characterised as involving 'feeling different', and having attributes of, and preferring the activities of the opposite sex, thus the suggestion of congenital gender inversion. Coleman (1982) discussed a pre-coming out stage when, according to his theory, sexual orientation is developing in childhood. He explained how, when a young boy displays gender non-conformity, 'minimally the child feels different, alienated and alone' and because the child is unaware of same-sex feelings, 'they cannot describe what is wrong ... (and) can only communicate their conflict through behavioural problems ...' (1982, p. 33). Troiden (1989, p. 50) discussed the individual's perception of the self as 'inadequately feminine or masculine' and the individual seeing this as evidence of their 'homosexuality'. For example Troiden (1989, p. 50) describes a boy speaking of childhood 'feelings of difference and not belonging ... I never learned to fight ... I was fond of pretty things ...' And girls' comments including '... I was more independent, more aggressive, more outdoorish.'

There are a number of important unanswered questions. What does 'feeling different' actually mean? Why do children behave in gender non-conforming ways? The common assumption, as can be seen in the writings of theorists of 'homosexuality', seems to be that it is because of an innate (albeit unconscious to the individual child) same-sex sexual orientation. For example, Blum (1998, p. 2) commenting on Dean Hamer's findings of genetic markings on the $\mathrm{X}$ chromosome of gay men, reports 'scientific research (that male sexual orientation) ... may be as much as $70 \%$ determined at birth. There's a measure of comfort in this research. It has helped to explain the uncomfortable feeling of difference experienced by many gays from an early age' (my italics). She acknowledges that there were not commensurate markings on the $\mathrm{X}$ chromosomes 
of lesbians (Blum, 1998, p. 84). Additionally Blum and other theorists do not consider that the 'feeling of difference' documented in the theories of 'homosexual' identity formation could for example, result from the condemnation a child experiences for not conforming to gender roles, rather than from innate sexual orientation, or, according to Haldeman (2000, p. 193) the feelings of difference could be 'normal responses' to disapproval and hostility from family and peers rather than from the condition of GID. Nor do researchers of 'homosexuality' and homosexual identity formation who adhere to this view consider the possibility that gender non-conforming behaviour in girls may result from awareness and rejection of sex-role restrictions.

Theories of a link between gender and same-sex sexuality nevertheless are supported by the many studies which demonstrate that to varying degrees gay men and lesbians recall gender non-conforming behaviour in childhood. However most of this research has been on gay men (Whitam \& Zent, 1984; Green, 1985; Phillips \& Over, 1992; Bem, 1996; Levay, 1996). Significantly less research has been done on gender nonconforming behaviour in lesbians. Research that includes lesbian respondents has been conducted by Saghir and Robins (1973), Whitam and Mathay (1991), Phillips and Over (1995) and Bem (1996). Even less research has included, as a control, the experiences of heterosexual women and men, although Phillips and Over (1995) and Bem (1996) are among the few who did include heterosexual women in their research.

Interestingly, some theorists have acknowledged evidence that gender non-conformity in childhood does not necessarily indicate adult same-sex sexuality. Troiden (1979, 1989), who discusses childhood gender non-conformity in his theories, also recognises that 'homosexual' meanings may be ascribed to gender non-conformity. For example he admits that heterosexual men, as well as gay men, may recall childhood feelings of difference. Bell et al. (cited in Minton \& McDonald, 1984) reported that almost half of their 'homosexual' male respondents were typically masculine in childhood, and that almost $25 \%$ of the heterosexual men were not masculine in childhood. Recent research by Rosal (2000) studied the relationship between gender typical behaviour in childhood and male adult same-sex sexuality. The study looked at factors such as early family, peer and romantic relationships in childhood and early adulthood. However, they could find no explanation as to why some gender conforming children develop into homosexual adults and others into heterosexual adults. Yet despite recognition of such contradictions the idea of same-sex sexuality as gender inversion persists. The influence of the different, but gendered, patriarchal, social and political contexts in which girls and boys live and are socialised was not studied. These issues are explored in the next section.

\section{The influence of the dominant ideology}

The idea of same-sex sexuality as congenital gender inversion has become entrenched in western culture, and is adhered to not only by researchers and theorists of 'homosexuality' but also by lesbians and gay men whose perception of themselves, as demonstrated in my research, is influenced by the values, attitudes and beliefs of the dominant culture. As a result of the belief that a 'homosexual' person possesses characteristics, and therefore behaviour, of the opposite sex, even many lesbians and gay men, while forming a 'homosexual' or lesbian identity, look for signs of inversion in themselves and endeavour to recall gender non-conforming childhood experiences. In my research I have found that it is particularly those lesbians who favour biological explanations for their sexuality, who reflect on their childhood, and interpret incidences of gender non-conformity as evidence of their innate lesbianism. 
My research has shown how many women weave the theories of the dominant ideology into their explanations of their experiences. I interviewed women who developed a lesbian identity in three different social periods. In each of these periods the dominant ideology about lesbianism differed significantly. The first period is between 1950 and 1970. The dominant belief about the aetiology of lesbianism, prior to the second wave women's movement, was that it was caused either by faulty or dysfunctional nurturing, or by a biological abnormality (Browning, 1984; Blumenfeld \& Raymond, 1988; Magee \& Miller, 1992). In both cases the individual is seen to possess characteristics and behaviour of the opposite sex.

The period between 1970 and the early 1980s was the height of the feminist era. The 1970s was an era of 'freeing up' of restrictive social norms (Browning, 1984). Feminists such as Oakley (1972), and see also Delphy (1993), rejected the notion that gender differences were biologically based, and proposed not only that gender was socially constructed, but that the constructed notions of gender were used to subordinate women. Mackinnon (1989, p. 128) describes gender as being caused by 'the social requirements of heterosexuality, which institutionalises male dominance and female sexual submission.' Although a biological basis for 'homosexual' orientation was still the dominant theory in the 1970s and 1980s, there was also discussion about the possibility of choosing to be lesbian and political lesbianism (see Gearhart, 1974; Browning, 1984), although there was little academic research around the issue of choice. The first time the existence of a relationship between gender and sexuality was challenged by researchers and theorists was during the years of the second wave women's movement. My research also shows that the identical experience of childhood gender non-conformity, is given totally different meanings by women who reject biological explanations for their sexual orientation and those strongly influenced by a different ideology, such as feminism.

The late 1980s and 1990s has witnessed a movement to political conservatism and, as suggested by Faludi (1992), and Oakley and Mitchell (1997), increased antagonism to feminism. In the 1990s there has been a resurgence of research attempting to establish a biological basis for 'homosexuality' (see, for example, Bailey \& Pillard, 1991; Hamer et al., 1993; LeVay, 1993, 1996) thus suggesting that heterosexuality is the normal sexuality (Kitzinger, 1993). This research has been given wide prominence in the media thereby once again reinforcing the idea that same-sex sexuality has a biological basis and that same-sex sexuality is gender inversion.

Many of the lesbians in my research did not speak of gender non-conformity in childhood. However lesbians who gave biological explanations for their sexuality also reflect on their life experience, especially childhood, in a search for evidence of their innate lesbianism. Respondents in this study, who became lesbians before feminism and in the late 1980s and 1990s, and who believe their lesbianism is innate, mostly incorporated views of gender non-conformity and 'latent homosexuality' into the stories of their experience of becoming lesbians.

The following comments by women who participated in my study, who believed in a biological basis for their lesbianism, demonstrate how they gave lesbian meanings to childhood gender non-conformity. They cited experiences such as preferring boy's games as evidence of their innate lesbianism. One woman explained, 'As a child I always felt different. I preferred to do boy's things in play. I was not feminine, I was a tomboy and not interested in playing with dollies.' Another woman said that, 'I thought of myself as a boy, dressed as a boy, tried to wee like a boy ... . My family wanted a boy so I tried to be a boy,' and a third woman said, 'I figured because I was a tomboy, my feelings 
for girls was supposed to be masculine and that I really want to be a man. In primary school I enjoyed boys' things. I took the boys' role in sex play, I enjoyed kissing girls.'

That gay men and lesbians may be reconstructing and reinterpreting childhood experiences in light of their learned information about 'homosexuality' has been acknowledged by some theorists, for example Troiden (1979) and Phillips and Over (1995). Such retrospective reinterpretation occurs when, having formed a 'homosexual' identity, a person reflects back on childhood experience and imagines they were always different, whereas it is possible a heterosexual person may have also had frequent feelings of being different. Troiden explained how the feelings of difference in childhood described by many gay men can be reinterpreted by a heterosexual adult male as, for example, signs of artistic sensitivity, whereas the same feelings might be reinterpreted by a gay man, as the 'first stirrings of homosexual interest' (Troiden, 1979, p. 364). Phillips and Over (1995) acknowledge that recall may not be an accurate indicator. Phillips and Over (1995), who in a study of recalled childhood experiences of heterosexual, bisexual and lesbian women, found that lesbians reported greater gender non-conformity than heterosexual women, warn about retrospective interpretation and acknowledge that some respondents may recall and describe their childhood experiences, including tomboyism, in ways that are consistent with their adult sexual identity and their understanding of lesbianism. Influenced by the dominant values and beliefs about same-sex sexuality, lesbians and heterosexual women are likely to place different emphasis on experiences. For example, heterosexual women are more likely to remember gender conforming behaviour and lesbians are more likely to remember tomboy behaviour. Phillips and Over (1995), commenting upon the high number of heterosexual women who were gender non-conforming, also acknowledge that while '... recall provides an adequate description of childhood there is not a uniform association between childhood experiences and sexual orientation as an adult.'

In my research many of the women were conscious of re-examining childhood experiences and attributing lesbian meanings to them. Few of my respondents however, actually claimed to be aware of feeling different at the time, except those who were aware of resenting the freedom and privileges of their brothers or other boys, and the restrictions on their own activities. Most of these women claimed to have chosen to become lesbians. The women who believed they were born lesbians mostly identified these events as evidence of innate lesbianism after they started the coming out process, that is during the formation of a lesbian identity. For some this was well into adulthood. Interestingly when I asked some of the lesbians who reinterpreted gender non-conforming childhood events as evidence of innate lesbianism, whether they equated lesbianism with masculinity the answer was a resounding 'No', followed by confusion as they realised they had potentially contradicted themselves.

\section{Gender bias and androcentrism in discussions of childhood gender non- conformity}

The connection of same-sex sexuality with gender non-conformity has been made largely as a result of studies into the childhood experiences of gay men. Research that has included lesbians has started from the assumption that their experiences will be similar. Consequently evidence from the experiences of lesbians that challenges the findings of a connection between same-sex sexuality and childhood gender non-conformity has been ignored or dismissed. An example of such androcentricity is the theory put forward by psychologist Daryl Bem (1996). Bem's theory is an example of ignoring the role of 
gender and political context, when theorising about the social experiences of women and men. Peplau et al. (1998) too argued that Bem has formed his theory from an androcentric perspective and failed to take into account the gendered political context in which girls and boys are socialised.

Bem (1996) proposed a developmental theory which he called 'exotic-becomes-erotic' (EBE). This theory relies heavily on gender non-conformity in childhood. According to his theory childhood temperament, such as a tendency toward aggression, leads to either gender conformity or non-conformity in terms of play activity and choice of playmate. For example a boy with a passive nature will avoid rough and tumble play, seek out girls as playmates, and engage in sex-atypical (gender non-conforming) behaviour. These boys will then feel different from their same-sex peers and perceive them as exotic.

According to Bem's theory every child experiences heightened autonomic arousal in the presence of children who they see as different. The autonomic arousal, he explains, can be felt as contempt for girls in the male typical child, and timidity and apprehension in the presence of boys for the female typical child (1996, p. 321). The gender conforming boy will feel this with girls, and the gender non-conforming boy will feel this with boys. The example he gives is, of the female typical boy who is taunted and labelled a sissy for his gender non-conformity. In later years, he explains, this autonomic arousal becomes an erotic/romantic attraction. Thus in Bem's words 'the exotic becomes erotic' (1996a, p. 321). Although he acknowledges that girls are less likely to be punished by female peers than boys for gender non-conformity, he makes the assumption that gender non-conformity for girls also leads to eroticisation of the sex-typical girls.

An examination of the political context in which the events occur lead to a different interpretation. Haldeman (2000, p. 194) contends that 'society endorses masculine behaviour more readily than feminine behaviours' and cites D'Augelli who pointed out that tomboys are mimicking the more desired masculine behaviours. As both girls and boys learn, through the construction of masculinity (Connell, 1987, 1995; Messner, 1992; Messner \& Sabo, 1994), that male characteristics and behaviour are desirable, it is indeed unlikely that tomboys (who are like boys) are harassed by gender conforming girls, in the same way that male sissies are harassed by gender conforming boys. Peplau et al. (1998, p. 392) claim that they are not harassed. They cited studies that found tomboys to be 'popular, cooperative, helpful, supportive of others ... and were regarded as leaders.' Indeed that they were just as popular as gender conforming girls. According to John Money, (1986) gender conformity is more important for boys, and boys are watched more closely than girls for gender non-conforming behaviour. They are also more likely to be heavily sanctioned. This is confirmed by Thorne (1990, p. 110) who cautions on the need to consider social processes. Thorne explains that in late primary school sissies are more often teased and harassed by both girls and boys, while tomboys are less stigmatised and do not experience the same level of derision (1990). It is also true that while gender conforming boy children may hold girls in contempt, the reverse is not necessarily true. Girls may prefer to play with girls, but there is no evidence that they hold boys in contempt, or indeed that they feel timidity or apprehension. There is no evidence either that gender conforming girls do not want to play with tomboys, because they feel antipathy or contempt. On the contrary Peplau et al. acknowledge that while, 'In the eyes of many children (both sexes) and adults, a "sissy" is about the worse thing that a boy can be' (1998, p. 392) they cite another study that found 'children rated the girls who played a masculine game with boys as most popular and the boy who played a feminine game with girls as least popular' (1998, p. 392). 
TABLE 1. Gender conforming and gender non-conforming behaviour in men and women (expressed in \%)

\begin{tabular}{lccccc}
\hline & \multicolumn{2}{c}{ Men } & & \multicolumn{2}{c}{ Women } \\
\cline { 2 - 3 } \cline { 5 - 6 } & Gay & Heterosexual & & Lesbian & Heterosexual \\
\hline Had not enjoyed sex typical activities & 63 & 10 & & 63 & 15 \\
Enjoyed sex-atypical activities & 48 & 11 & & 81 & 61 \\
Atypically sex-typed (masculinity or femininity) & 56 & 8 & & 80 & 24 \\
Most childhood friends opposite sex & 42 & 13 & & 60 & 40 \\
\hline
\end{tabular}

Additionally, in Bem's theory, the gender comparison does not hold at the point where the exotic becomes erotic. It is understandable that effeminate men become sexually attracted to masculine men, because, as has been discussed, in our culture masculinity is desired and admired. For tomboys an analogy cannot be made. The gender conforming female belongs to the inferior class of 'women' and they are therefore less likely to experience the transformation of the exotic (inferior females) to the erotic (inferior females). Bem has not taken into consideration institutionalised gender power relationships. The status and power differences between women and men was acknowledged by Cass (1990, p. 262) when she maintained, 'there is probably less incentive for the gay male to reject the male sex-role with its focus on independence, power and intellect than there is for the lesbian to reject the female sex-role.'

It is possible that gender non-conforming boys are simply not interested in rough and tumble play and that gender non-conforming girls prefer more active play. Applying the label of 'homosexuality' to gender non-conforming behaviour obfuscates the possibility that 'gender' is not essential, and that all children may be capable of behaving in gender non-conforming ways, indeed that gender categorisation and gender conformity is socially constructed. While girls may be rebelling against restricting sex-roles, it is not impossible too that some boys may enjoy more passive or artistic pursuits instead of, or as well as, active rough and tumble boys' play. The fact that previous researchers also found that many heterosexual men were gender non-conforming in childhood attests to this suggestion.

\section{Heterosexual women and childhood gender non-conformity}

Examination of research on gender non-conformity reveal significant inconsistencies. Inconsistencies firstly exist in the disparity between lesbians and gay men who were gender non-conforming, and the many lesbians and gay men who were gender conforming, and secondly in the high numbers of heterosexual women who report gender non-conformity. To associate childhood gender non-conformity in girls (tomboy behaviour) with adult lesbianism makes no sense at all when heterosexual women's experiences are taken into consideration.

Research that has included heterosexual women has found that many were gender non-conforming in childhood. In both Phillips and Over's (1995) and Bem's (1996) studies at least $60 \%$ of heterosexual women were also tomboys and, it is interesting to note that overall, fewer gay men than heterosexual women preferred opposite sex play and opposite sex friends in childhood. These discrepancies are apparent in the figures in Table 1 which are among those used by Bem (1996, p. 322) to demonstrate higher gender non-conformity in 'homosexual' men and lesbians than in heterosexuals.

Referring to these statistics, Bem comments that gay men were significantly more likely 
than heterosexual men to report gender non-conformity and to have girls as childhood friends. He then maintains that 'the corresponding comparisons between lesbian and heterosexual women was also large and significant.' Bem did not comment upon the more than significant numbers of heterosexual women, than heterosexual men, who enjoyed sex-atypical activities. The fact that more heterosexual women than even gay men had enjoyed boys' activities in childhood was explained in terms of, 'differences between women and men in how their sexual orientations are distributed in our society' (1996, p. 322). More importantly he did not attempt to explain why significantly more lesbians than gay men enjoyed sex atypical activities.

Similarly in their study of recalled childhood gender non-conformity, Phillips and Over (1995) also found that lesbians recalled more gender non-conforming behaviour and less gender conforming behaviour than heterosexual women (1995, p. 16). It is significant also that, in Phillips and Over's study, while $77 \%$ of lesbians and $77 \%$ of bisexual women were considered a tomboy as a child, so were $63 \%$ of the heterosexual women, and while $86 \%$ of lesbians engaged in gender non-conforming behaviour, so did $63 \%$ of the heterosexual women.

Both Phillips and Over's (1995) study and Bem's (1996) study revealed that a significant number of heterosexual women preferred gender non-conforming activities in childhood. Given that tomboysim is one of the childhood experiences most often spoken of in relation to a biological basis for lesbianism, the high number of heterosexual women who report gender non-conformity makes such conclusions questionable.

The significance of the figures is that both lesbians and heterosexual women preferred sex-atypical (male) activities more than gay men. Furthermore not only did more lesbians than gay men report that most childhood friends were opposite sex, but almost as many heterosexual women $(40 \%)$ as gay men $(42 \%)$ seemed to prefer opposite sex childhood friends. Peplau et al. too, noted that tomboyism is widespread among American girls and cites several other studies that found high levels of gender non-conformity among both lesbian and heterosexual women (1998, p. 392). Furthermore they noted that 'Most tomboys, even those who are fairly extreme in their gender non-conformity, grow up to be heterosexual' (1998, p. 393).

It is clear that the literature on childhood gender non-conformity has revealed discrepancies between the experiences of gay men and lesbians and between lesbians and heterosexual women that have remained unchallenged and unexplained. These discrepancies can, to a great extent, be explained by the experiences of the women in my research who believe they chose to be lesbians. Researchers, in their interpretation of findings about gender non-conformity, do not discuss the important political dimension, that for women, childhood gender non-conforming behaviour and subsequent decisions to become lesbians may result from factors such as an awareness that marriage means dependence, restriction on activities and subordination. It is possible that gender non-conforming behaviour may be a rejection of restrictions on freedom and play and of the female sex-role. As can be seen by the numbers of heterosexual women in such research, who also recall gender non-conformity, the connection between gender non-conformity and lesbianism is questionable. What Bem's and Phillips and Over's findings highlight is not so much that 'homosexual' people are, or were, gender non-conforming, but that both lesbians and heterosexual women prefer that which is associated with masculinity, in a culture that constructs the masculine as dominant and superior, and the feminine as subordinate and inferior. A view that has certainly been emphasised by lesbians in my study, is that male typical activities are perceived as allowing more freedom and fun than female typical activities. 


\section{A radical feminist explanation for childhood gender non-conformity}

Radical feminists reject the idea of an essential gender, see for example Mackinnon (1989), Delphy (1993) and Jeffreys (1997). Other theorists such as Corbett, propose that gender is a social construction. Corbett, believing that effeminacy in males is a normal though contested realm of human experience, notes that for many theorists of Gender Identity Disorder 'the social construction of appropriate gender is dismissed' (1999, p. 119). Elise (1999) sees gender non-conformity, that is, tomboyism as a common phenomenon in female development. Common interpretations of childhood gender non-conformity including that of Bem (1996) ignore the different political contexts in which girls and boys are socialised. For boys, rough and tumble play, competitive sport and a degree of aggression are viewed positively because they are considered to be masculine characteristics. Passive behaviour, as discussed in the previous section, is considered to be inappropriate for boys, but appropriate for girls (Thorne, 1990). The beliefs that so-called effeminate behaviours are inappropriate for boys, perpetuates the inequalities of gender. Interestingly Friedman (1988) found that negative attribution of effeminate behaviour in boys resulted in low masculine self-image, scapegoating and rejection by peers, and often rejection by the father. Burke (1996) and Pleak (1999) describe similar observations. This is likely to be because the boys were engaging in behaviours associated with femaleness and subordination.

Women in my study who believe they chose to be lesbians also spoke of gender non-conforming characteristics and behaviour. However they interpreted gender nonconformity as a contributing factor in their decision to choose lesbianism only insofar as they were rejecting the restrictions placed on girls and the female sex-role. Many of them reported gender non-conformity and 'feelings of difference', but explained those feelings in terms of a rejection of the rigidity of gender roles, and resentment about boys' freedom and choices, and not to the idea that their childhood gender non-conformity and feelings of difference were evidence of an innate lesbianism. The difference lies in the interpretation of such feelings and experiences. In this context gender non-conformity becomes an act of social and political resistance. For example, while reflecting on her childhood, one woman in my research explained her feeling of frustration at the 'double standards and unfairness with respect to the inequalities experienced by women.' She explained how she resisted 'confining gender roles by a rejection of anything considered feminine and a desire to compete on equal terms with boys.' Another woman commented that, 'I resented the unequal roles of women and men when I was young.'

Surprisingly, even without the influence of feminism, a number of respondents who developed a lesbian identity prior to the 1970s recognised that their childhood feelings of difference were resentment about gender restrictions and a desire for the freedom and more exciting life allowed to boys. One woman who came to lesbianism in the early 1960s does not believe she was born a lesbian. She understood that she was rejecting women's lifestyle in her childhood, 'I knew I did not want to be stuck in a house washing dishes for a man.' She recalls observing her mother,

... inside, cleaning and boring and my father always doing exciting things, I always preferred to be with my father, I identified with my father's life as being free life, the real life ... mum's life, I never wanted to be there. I was rejecting women's lifestyle.

Likewise another woman who also became a lesbian in her teens in the early 1960s described similar experiences. She recalls rejecting gender roles, 
I just knew I didn't want to be like my mother, at home running home and family ... I wanted a career and higher education. ... the sexual thing, that was a natural progression ... I want to run my own life, I don't want some man running it - the power thing ...

She recalls that from about the age of seven she wanted to be a boy, 'I behaved in boys' ways instead of girls ... I wanted to be a boy.' However even then she realised, ' ... not physically, it was their freedom I wanted ... ... In games I took the male role and resented being pushed into doing girls' stuff ... boys were allowed to do things girls weren't.' She explained how she rejected gender roles and was also conscious of rejecting a lifestyle she didn't want.

The belief in the essentialist nature of gender and same-sex sexuality is especially strongly challenged by the experiences of women who became lesbians as a result of feminist awareness. They are women who started from an understanding of gender socialisation and the nature of patriarchy and gender (Ettorre, 1980; Leeds Revolutionary Feminist Group, 1981). They recognise that any feeling of difference and desire for male activities is more likely to be resentment about and rejection of gender restrictions rather than an indication of innate 'homosexuality' (Ettorre, 1980). Lesbians in my research who developed a lesbian identity through feminism, and through what they saw as social/political choice, rarely cited childhood experiences. They rejected the idea that their childhood experiences could be an indication of innate lesbianism. One political lesbian in my study described her feelings, '... I l looked at heterosexual relationships, saw the oppression, saw the inequality ....'

Many researchers, being exposed only to biological understandings of gender and sexuality, and observing what they would have considered 'tomboy' behaviour, would have seen evidence of innate lesbianism instead of ordinary childhood play, or the rejection by girls, of the rigidity of gender roles. In a telling article in a popular lesbian magazine, Alix Dobkin, a feminist in the 1970s, recognises the pervasive influence on lesbians of changing ideologies. On a recent radio programme she heard lesbians tell the same story that lesbians had been telling for decades, of feeling different, not feeling like girls and envying brother's freedom and power. Whereas some lesbians in my research related such stories as evidence that their lesbianism was biologically based, these lesbians had been exposed to the rhetoric of GID and transsexualism and believed themselves to have been born in the wrong body. It is disturbing to note that at least one lesbian Dobkin personally knew of, was being encouraged to undergo sexual realignment surgery (Dobkin, 2000, p. 37). The changing dominant ideology seems once again to be influencing the meaning women give to their experiences, so now, the same experience of gender non-conformity is, for some, an indication of being born in the wrong body.

On the other hand it is heartening to note that the women in my research who believe they chose to be lesbians were more aware of their childhood gender non-conformity as a political act of resistance. At the very least the findings from my study and closer examination of the literature on childhood gender non-conformity and gender identity disorder raise a number of questions.

The main question surrounding gender non-conformity is that of cause and effect. Does the experience of gender non-conformity increase the possibility that an individual will be subtly conditioned by the idea of same-sex sexuality or is gender non-conformity caused by innate 'homosexuality'? It is unclear in the end, in the wealth of research and discussions about sexuality, what, if anything, gender non-conforming behaviour in childhood means or is evidence of. For example if $77 \%$ of lesbians report gender 
non-conformity, but also 63\% of heterosexual women (Phillips \& Over, 1995) and 81\% of lesbians but also $61 \%$ of heterosexual women enjoyed sex-atypical activities (Bem, 1996), it seems highly improbable that an essential connection can be made between gender non-conformity and lesbianism. It is not enough to know that women engaged in gender non-conformity. It is also necessary to understand their reasons for engaging in gender non-conforming behaviour.

Most important is an examination of the idea of 'normal' gender characteristics and behaviour. As acknowledged by Rottnek (1999, p. 2) 'The very concept of "gender non-conformity"... assumes a normal or acceptable range of gender expression.' So the discussion returns to questions of what is normal, who decides what is normal and the reasons for their decision. It would be of interest here to explore the ways in which ideas of gender non-conformity have come to serve the agenda of biological determinism. Feminists such as Mackinnon (1989), Delphy (1993) and Jeffreys (1997) contend that constructed notions of gender differences were, and indeed are, used to subordinate and disadvantage women. The idea of a biological construction of 'homosexuality' based on gender inversion, and drawing upon the notion of childhood gender non-conformity to support it, underpins a patriarchal culture in the same way that the belief in biological or essential gender differences does. The idea of gender difference is fundamental to the social and political structure of western culture.

Further research that is not focussed toward same-sex sexual orientation, or the idea of gender non-conformity as a pathology needs to be done to clarify the reasons for, and meaning of gender non-conforming behaviour. If indeed all human beings are born with the potential to be sexual, rather than with a particular sexual orientation, then gender non-conformity would not be interpreted as evidence of same-sex sexuality. If conceptions of gender were more fluid and the characteristics and behaviour now considered to be gendered were equally available to females and males than the very idea of something like gender non-conformity or gender identity disorder would be absurd.

\section{REFERENCES}

Bailey, J. M. \& Pillard, R. G. (1991) A genetic study of male sexual orientation, Archives of General Psychiatry, 48, pp. 1089-1096.

Bell, A. P., Weinberg, M. S. \& Hammersmith, S. K. (1981) Sexual Preference, It's Development in Men and Women (Bloomington, Indiana University Press).

BEM, D. (1996a) Exotic becomes erotic: a developmental theory of sexual orientation, Psychological Review, 103 (2), pp. 320-335.

Bloch, I. (1908) The Sexual Life of Our Times (London, William Heinemann).

Blum, D. (1998) What made Troy gay, Health, 12 (3), pp. 82-86.

Blumenfeld, W. \& Raymond, D. (1988) Looking at Gay and Lesbian Life (Boston, Beacon Press).

Browning, C. (1984) Changing theories of lesbianism, challenging the stereotypes, in: T. DARTY \& S. PotTER (Eds) Women - Identified Women (Palo Alto, Mayfield Publishing Company).

Burke, P. (1996) Gender Shock: exploding the myths of male and female (New York, Bantam Doubleday Dell Publishing).

Byne, W. \& Parsons, B. (1993) Human sexual orientation, the biologic theories re-appraised, Archives of General Psychiatry, 50, pp. 228-238.

Cass, V. C. (1990) The implications of homosexual identity formation for the Kinsey Model and scale of sexual preference, in: D. MCWhirter, S, SAnders \& J. M. ReInisch (Eds) Homosexuality/Heterosexuality: concepts of sexual orientation (New York, Oxford University Press).

Coleman, E. (1982) Developmental stages of the coming out process, in: Homosexuality and Psychotherapy (The Haworth Press Inc.) pp. 31-42.

Connell, R. W. (1987) Gender and Power: society, the person and sexual politics (Cambridge, Blackwell Publishers Ltd).

Connell, R. W. (1995) Masculinities (St Leonards, NSW, Allen and Unwin). 
Corbett, K. (1998) Cross-gendered identifications and homosexual boyhood: toward a more complex theory of gender, American Journal of Orthopsychiatry, 68 (3), pp. 352-360.

Corbett, K. (1999) Homosexual boyhood: notes on girleyboys, in: M. RotTnek (Ed.) Sissies and Tomboys: gender nonconformity and homosexual childhood (New York, New York University Press).

DAnk, B. (1971) Coming out in the gay world, Psychiatry, 34, pp. 180-197.

Darty, T. \& Potter, S. (1984) Women-Identified Women (Palo Alto, Mayfield Publishing Company).

DelPhy, G. (1993) Rethinking Sex and Gender, Women's Studies International Forum, 16 (1), pp. 1-9.

Dobkin, A. (2000) The great mother and child reunion, Lesbian Neres, 25 (9), p. 36.

Duplock, S. (1997) Case Studies in Existential Psychotherapy and Counselling (Chichester, John Wiley and Sons).

ELISE, D. (1999) Tomboys and cowgirls: the girl's disidentification from the mother, in: M. Rottnek (Ed.) Sissies and Tomboys: gender nonconformity and homosexual childhood (New York, New York University Press).

Eluis, H. \& Symonds, J. A. (1897) Sexual Inversion (Wilson and Macmillan, Bedford Row, England) (first published 1897).

EtTorre, E. M. (1980) Lesbians, Women and Society (London, Routledge Kegan Paul).

FALUdi, S. (1992) Backlash: the undeclared war against women (London, Chatto \& Windus).

FrIedman, R. C. (1988) Male Homosexuality: a contemporary psychoanalytic perspective (New Haven, CT, Yale University Press).

Gearhart, S. (1974) Loving Women Loving Men (San Francisco, Glide Publications).

Green, R. (1985) Gender identity in childhood and later sexual orientation: follow-up of 78 males, American Fournal of Psychiatry, 142, pp. 339-341.

Haldeman, D. G. (2000) Gender atypical youth: clinical and social issues, School Psychology Review, 29 (2), pp. 192-200.

Hamer, D., Hu, S., Magnuson, V. L., Hu, N. \& Pattatuci, A. (1993) A linkage between DNA markers on the X chromosome and male sexual orientation, Science, 261, pp. 421-427.

Jackson, S. (1978) On the Social Construction of Female Sexuality (London, Women's Research and Resources Centre Publications).

Jackson, S. (1996) Heterosexuality and feminist theory, in: D. Richardson (Ed.) Theorising Heterosexuality (Buckingham, Open University Press).

Jayaratne, T. E. (1983) The value of quantitative methodology for feminist research, in: G. Bowles \& R. D. KLEIN (Eds) Theories of Women's Studies (London, Routledge and Kegan Paul).

JEFFREYs, S. (1996) Return to gender: post-modernism and lesbianandgay theory, in: D. BELL \& R. KLEIN (Eds) Radically Speaking, Feminism Reclaimed (Melbourne, Spinifex).

Jefrreys, S. (1997) The Idea of Prostitution (Melbourne, Spinifex).

Kallman, F. (1951) Twin studies in relation to adjustive problems in men, Transactions of the New York Academy of Sciences, 13, pp. 270-275.

Kitzinger, G. (1987) The Social Construction of Lesbianism (London, Sage Publications).

Kitzinger, G. \& Perkins, R. (1993) Changing Our Minds: lesbian feminism and psychology (London, Onlywomen Press).

Leeds Revolutionary Feminist Group (1981) Political lesbianism: the case against heterosexuality, in: OnLywomen (Eds) Love Your Enemy (London, Onlywomen Press).

Levay, S. (1993) The Gay Brain (Cambridge, MA, MIT Press).

Levay, S. (1996) Queer Science (Cambridge, MA, MIT Press).

MacKinnon, C. (1989) Toward a Feminist Theory of State (Cambridge, Harvard University Press).

Magee, M. \& Miller, D. (1992) "She foreswore her womanhood": psychoanalytic views of female homosexuality, Clinical Social Work Journal, 20 (1), pp. 67-85.

Mass, L. (1990) Sissiness as metaphor: a conversation with Richard Green, in: Dialogues of the Sexual Revolution, Vol. 1 (Binghampton, NY, Hayworth Press).

Messner, M. (1992) Power at Play: sports and the problem of masculinity (Boston, Beacon Press).

Messner, M. \& Sabo, D. (1994) Sex, Violence and Power in Sports: rethinking masculinity (Boston, Beacon Press).

MeyenburG, B. (1999) Gender identity disorder in adolescence: outcomes of psychotherapy, Adolescence, 34 (134), pp. 305-313.

Minter, S. (1999) Diagnosis and treatment of gender identity disorder in children, in: M. RotTNek, Sissies and Tomboys: gender nonconformity and homosexual childhood (New York, New York University Press).

Minton, H. \& MCDonald, G. (1984) Homosexual identity formation as a developmental process, fournal of Homosexuality, 9 (2/3), pp. 91-103.

Money, J. (1986) Venuses Penuses: sexology sexosophy and exigency theory (Buffalo, NY, Prometheus Books).

OAKley, A. (1972) Towards a New Society: sex, gender and society (London, Maurice Temple Smith Ltd.). 
OAkley, A. \& Mitchell, J. (Eds) (1997) Who's Afraid of Feminism: seeing through the backlash (London, Penguin). Peplau, L., Garnets, L., Spalding, L., Conley, T. \& Veniegas, R. (1998) A critique of Bem's “exotic becomes erotic" theory of sexual orientation, Psychological Review, 105 (2), pp. 387-394.

Phillips, G. \& Over, R. (1992) Adult sexual orientation in relation to memories of childhood gender conforming and gender non-conforming behaviours, Archives of Sexual Behaviour, 21, pp. 543-558.

Phillips, G. \& Over, R. (1995) Differences between heterosexual, bisexual and lesbian women in recalled childhood experiences, Archives of Sexual Behaviour, 24, pp. 1-20.

PleAK, R. (1999) Ethical issues in diagnosing and treating gender-dysphoric children and adolescents, in: M. RotTnek (Ed.) Sissies and Tomboys: gender nonconformity and homosexual childhood (New York, New York University Press).

Plummer, K. (1975) Sexual Stigma: an interactionist account (New York, Routledge and Kegan Paul).

Plummer, K. (Ed.) (1981) The Making of the Modern Homosexual (London, Hutchinson and Co.).

Richardson, D. (1996) Theorising Heterosexuality (Buckingham, Open University Press).

RosaL, C. L. (2000) Boyhood masculinity and adult male homosexuality: early social relationships of some men in Los Angeles, in: Dissertation - Abstracts - International (unpublished thesis).

RotTnek, M. (1999) Sissies and Tomboys: gender nonconformity and homosexual childhood (New York, New York University Press).

SAGHIR, M. \& Robins, E. (1973) Male and Female Homosexuality: a comprehensive investigation (Baltimore, MD, Williams and Wilkins).

Thorne, B. (1990) Children and gender: constructions of difference, in: RHODE, D. L. (Ed.) Theoretical Perspectives on Sexual Difference (New Haven, Yale University Press), pp. 100-113.

Troiden, R. (1979) Becoming homosexual: a model of gay identity acquisition, Psychiatry, 42, pp. $362-373$. Troiden, R. (1989) The formation of homosexual identities, Fournal of Homosexuality, 17 (1/2), pp. 43-73.

Von Krafft-Ebing, R. (1906) Psychopathia Sexualis (adapted from the 12th German edition by F.J. Rebman.

WhitAM, F. \& ZENT, M. (1984) A cross-cultural assessment of early cross-gender behaviour and familial factors in male homosexuality, Archives of Sexual Behaviour, 13, pp. 427-439.

Whitam, F. \& Mathay, R. (1991) Childhood cross gender behaviour of homosexual females in Brazil, Peru, the Philippines, and the United States, Archives of Sexual Behaviour, 20, pp. 151-170. 
